\title{
EFICIÊNCIA E FITOTOXICIDADE DE FUNGICIDAS NO CONTROLE DE Drechslera teres EM SEMENTES DE CEVADA (Bordeum vulgare) ${ }^{1}$
}

\author{
PHYTOTOXICITY AND EFFICIENCY OF FUNGICIDES ON THE CONTROL OF \\ Dreschslera teres in Barley (Hordeum vulgare)
}

\section{Ricardo Silveiro Balardin ${ }^{2}$ Milto José Facco ${ }^{3}$}

\section{RESUMO}

O objetivo do experimento foi avaliar a eficiência e fitotoxicidade de cinco fungicidas aplicados no tratamento de sementes para o controle de Drechslera teres, agente causal da mancha reticulada em cevada. A produtividade da cultura foi afetada pelos fungicidas testados. Os fungicidas tebuconazole e triadimenol reduziram a altura das plântulas, enquanto que o difenoconazole reduziu significativamente a matéria seca $(30 \mathrm{~g} / 100 \mathrm{~kg}$ de sementes). $O$ efeito dos fungicidas sobre a emergência mostrou que difenoconazole $(30 \mathrm{~g} / 100 \mathrm{~kg}$ de sementes) e iprodine + thiram possibilitaram as maiores percentagens. Os fungicidas reduziram a incidência da Drechslera teres, o comprimento do coleóptilo e das radículas.

Palavras-chave: mancha reticulada, tratamento de sementes, fitotoxicidade, cevada.

\section{SUMMARY}

The aim of this experiment was to evaluate five fungicides normaly used as seed dressing on the control of Dreschlera teres, in barley. The yield was influenced by all fungicides tested. The height of seedlings was reduced by tebuconazol and triadimenol while dry matter was significantly reduced by difenoconazol (30g i.a./100kg of seeds). The higher percentage of emergency was obtained by difenoconazol ( $30 \mathrm{~g}$ i.a. $/ 100 \mathrm{~kg}$ of seeds) and iprodione + thiram. The five fungicides reduced the pathogen incidence, the coleoptile length and root lenght.

Key words: net blotch, seed treatment, phytoxicity, barley.

\section{INTRODUÇÃO}

O tratamento de sementes de cevada é recomendado para controle das doenças da parte aérea, pois reduz significativamente a fonte de inóculo inicial,

\footnotetext{
${ }^{1}$ Trabalho realizado através do convênio FATEC/CIBA-GEIGY Química S.A.

2 Engenheiro Agronomo, Professor Assistente, Departamento de Defesa Fitossanitária, Centro de Clencias Rurais, Universidade Federal de Santa Maria, 97119-900 - Santa Maria-RS.

${ }^{3}$ Engenheiro Agronomo, Ciba-Geigy Química S.A., 97060-002, Santa Maria-RS.
} 
principalmente considerando Dreschelera teres, agente causal da mancha reticulada (LUZ, 1982). Uma vez năo sendo realizado, a magnitude da fonte de inóculo inicial torna-se diretamente relacionada ao nível de infecçăo do patógeno. LUZ \& MINELLA (1982) e LUZ (1980) demonstraram que dentre os vários patógenos encontrados nas sementes de cevada, Cochlibolus sativus (Ito \& Korib) Dresh. ex. Dastur e Pyrenophora teres (Died.) Drech, foram os de maior incidência. LUZ (1982a) testou cinco produtos sistêmicos no tratamento de sementes de cevada para proteção contra o inóculo na semente e o inóculo na parte aérea de Pyrenophora teres observando controle eficiente da doença. BALARDIN \& LOCH (1987) observaram redução no poder germinativo e tamanho do coleóptilo de centeio e aveia bem como redução no tamanho de radículas de aveia, quando as sementes foram tratadas com thiram. Resultados obtidos por FORCELINI \& REIS (1987) mostraram que o melhor controle de Dreschelera teres foi proporcionado por iprodione, etiltrianol (tebuconazole) e triadimenol, sendo estes dois últimos os que melhor controlaram a transmissão do patógeno das sementes para a primeira folha. HAVAGGE \& SILVA (1980) observaram que o tratamento de sementes de cevada com fungicidas não apresentou efeito com relação a densidade de plantas a campo. Por outro lado, plantas originadas de sementes tratadas com thiram apresentaram o mais baixo índice de severidade da mancha reticulada. Este trabalho foi conduzido com a finalidade de verificar a eficiência de fungicidas aplicados em tratamento de sementes de cevada, no controle da mancha reticulada bem como avaliar a presença de efeitos fitotóxicos à cultura.

\section{MATERIAL E MÉTODOS}

O experimento de campo foi conduzido no município de Júlio de Castilhos, RS e as avaliaçð̃es de laboratório na Universidade Federal de Santa Maria, RS. O delineamento experimental utilizado no experimento de campo foi o de blocos ao acaso com quatro repetiçőes e seis tratamentos. A área da parcela experimental foi de $9,0 \mathrm{~m}^{2}(1,8 \times 5,0 \mathrm{~m})$, sendo utilizada uma densidade de 250.000 plantas/ha. Foram testados difenoconazole (25 e $30 \mathrm{~g}$ de i.a./100kg de sementes), iprodione + thiram $(50 \mathrm{~g}+150 \mathrm{~g}$ de i.a. $/ 100 \mathrm{~kg}$ de sementes), triadimenol ( $40 \mathrm{~g}$ de i.a./100kg de sementes) e tebuconazole ( $15 \mathrm{~g}$ de i.a./100kg de sementes). A aplicação ocorreu um dia antes da implantação do experimento através do método de via úmida ( $1 \%$ de água/volume de sementes). Os parâmetros avaliados foram: percentagem de emergência, número de plântulas com sintomas visíveis de mancha reticulada e rendimento de grăos. A determinação do número de plântulas com sintomas de mancha reticulada foi efetuada no estádio 2 de crescimento, conforme escala de Feekes \& Large apud LARGE (1956). Para identificaçăo da microflora fúngica das sementes iratadas com os fungicidas testados a campo foi utilizado o método de papel filtro (NEERGAARD, 1973) e o delineamento experimental foi o completamente casualizado com 4 repetiçőes. Após o tratamento de 400 sementes com os fungicidas, foram colocadas sobre papel filtro esterilizado umedecido com água destinada esterilizada em caixas gerbox, sendo incubadas durante 7 dias em câmara do tipo Fitotron, sob regime luminoso de 12:12h (luz:escuro) com lâmpadas do tipo luz do dia $(40 \mathrm{w})$, temperatura de 20 a $25^{\circ} \mathrm{C}$. A unidade experimental constou de 4 caixas germ-box com 25 sementes/caixa. No final do período de incubação foi identificado sob microscópio estereoscópico e/ou microscópio ótico com base em suas características morfológicas (BARNETT \& HUNTER, 1972). Para determinar a fitotoxicidade dos produtos foi medido o comprimento do coleóptilo e das radículas, em laboratório, e determinado a matéria seca e a altura das plântulas a campo. O comprimento do coleóptilo e de radículas foi obtido a partir de 400 sementes tratadas com cada ingrediente ativo e postas a germinar em caixas germbox em câmaras do tipo Biotronette Mark III, com regime luminoso de 12:12h (luz:escuro) com lâmpadas do tipo luz do dia (40w). A temperatura e o período de incubação utilizados seguiu as normas do Ministério de Agricultura para análise de sementes, sendo de $20^{\circ} \mathrm{C}$ durante 7 dias. A altura de plantas e a matéria seca foram obtidas a partir de material coletado aleatoriamente na área útil das parcelas experimentais. A determinação da matéria seca foi feita em estufa à $65^{\circ} \mathrm{C}$ durante $48 \mathrm{~h}$, ou ate que o peso permanecesse constante.

\section{RESULTADOS E DISCUSSÃO}

Na Tabela 1 é mostrado o efeito do tratamento de sementes sobre a produtividade, altura de plântulas e matéria seca, sendo observado que os fungicidas utilizados no tratamento de sementes permitiram ganhos de rendimento, apesar de que durante o ciclo da cultura os componentes do rendimento são afetados por diversos fatores. Relacionando-se o melhor tratamento com a testemunha, foi observado um ganho de $14 \%$ devido ao tratamento de sementes. Este resultado atesta a relevância do inóculo primário de Dres - 
chlera teres contido nas sementes como fator epidemiológico capaz de resultar em sintomas da doença suficientes para acarretar reduções no rendimento conforme já havia sido relatado por REIS (1981). A altura de plântulas foi significativamente reduzida por tebuconazole, sendo que os demais fungicidas não se diferenciaram estatisticamente da testemunha. Com relação à matéria seca, difenoconazole $(30 \mathrm{~g} / 100 \mathrm{~kg}$ de sementes) provocou o menor acúmulo enquanto que os demais fungicidas não foram significativamente afetados.

Tabela 1 - Efeito do tratamento de sementes sobre o rendimento $(\mathrm{kg} / \mathrm{ha})$, altura de plantas $(\mathrm{cm})$ e matéria seca da parte aérea (g). Júlio de Casti!hos, 1993.

\begin{tabular}{|c|c|c|c|c|}
\hline $\begin{array}{l}\text { Tratamentos } \\
\text { (g/100kg sementes) }\end{array}$ & $\begin{array}{l}\text { Produtividade } \\
\text { (kg/ha) }\end{array}$ & $\begin{array}{c}\text { Altura } \\
\text { (cm) }\end{array}$ & & $\begin{array}{l}\text { Aateria seca } \\
\qquad(\mathrm{g})\end{array}$ \\
\hline Difenoconazole 25 & $1.449,6 a^{*}$ & $11,15 a$ & & $5,10 a$ \\
\hline Difenoconazole 30 & $1.411,9 a$ & $11,27 a$ & & $4,77 \mathrm{C}$ \\
\hline Iprodione + Thiram $50+150$ & $1.435,5 a$ & $11,32 a$ & & $5,75 a$ \\
\hline Triadimenol 40 & $1.430,8 \mathrm{a}$ & $10,75 a$ & & $5,55 a$ \\
\hline Tebuconazole 15 & $1.397,7 a$ & 10,05 & $\mathrm{e}$ & $5,30 a$ \\
\hline Testemunha & $1.270,2 \quad d$ & $11,30 a$ & & $5,50 a$ \\
\hline C.V. (\%) & 4,47 & 4,53 & & 8,51 \\
\hline Média geral & $1.399,30$ & 10,97 & & 5,33 \\
\hline
\end{tabular}

* Médias seguidas da mesma letra não diferem pelo teste de Duncan ao nivel de $5 \%$.

$\mathrm{Na}$ Tabela 2 é apresentado os resultados da emergência e o número de plântulas com sintomas da mancha reticulada obtidos a campo. Difenoconazole (25 - 30g/100kg de sementes) e iprodine + thiram destacaram-se dos demais tratamentos, permitindo ganho significativo no número de plântulas emergidas com relação a testemunha.

$\mathrm{Na}$ Tabela 3, é mostrado que os fungicidas provocaram redução significativa no comprimento do coleóptilo, sendo que a maior redução foi causada por triadimenol. Tebuconazole foi o único fungicida que não se diferenciou da testemunha quanto ao comprimento de radícula, BALARDIN \& LOCH (1987) já haviam observado efeito semelhante sobre centeio e aveia. A redução no número de plântulas com sintomas da mancha reticulada foi de até 24 vezes quando considerado o melhor tratamento em relação à testemunha. Este resultado implica em apreciável redução na quantidade de inóculo secundário da doença e, conseqüentemente, na velocidade de progresso da doença, o que é um dos principais objetivos do tratamento de sementes com fungicidas. Todos os fungicidas testados apresentaram um número inferior de plântulas com sintomas da mancha reticulada, quando comparado à testemunha, mostrando a importância do inóculo inicial originado da semente bem como o efeito dos fungicidas no seu controle, conforme observação já realizada por FORCELINI \& REIS (1987). Este resultado refletiu-se no rendimento, cunforme apresentado na Tabela 1, demonstrando a importância do inóculo primário presente na semente também como fator de redução direta do rendimento. Por outro lado, a redução no comprimento do coleóptilo e da radícula provocada pelos fungicidas, não influenciou o rendimento, já que provavelmente este efeito tenha tido repercussão apenas durante o estágio inicial de estabelecimento das plântulas. LUZ (1982a) observou controle eficiente do patógeno nos grãos infectados pela aplicação de fenapronil, imazalil, nuarimol e triadimenol sem contudo refletir-se em aumento de emergência: nuarimol e triadimenol protegeram a parte aérea contra 0 ataque do patógeno por um período superior a 40 dias enquanto que fenapronil exerceu esta proteção por um período entre 20 e 30 dias e imazalil não foi eficiente nesta fase; nuarimol e triadimenol propporcionaram redução no número de sementes infectadas e sev'eridade do ataque de Pyrenophora teres, afetando o rendimento de grãos; nuarimol, triadimefon e triadimenol apresentaram efeitos fitotóxicos nas plântulas, confirmando os resultados obtidos. Neste trabalho nãc houve referência sobre a origem do inóculo, se da semente ou de outra fonte.

Tabela 2 - Percentagem de emergência e de plântulas com sintomas da mancha reticulada avaliados a campo. Júlio de CastiInos, 1993.

\begin{tabular}{lcc}
\hline $\begin{array}{l}\text { Tratamentos } \\
(\mathrm{g} / 100 \mathrm{~kg} \text { de sementes) }\end{array}$ & $\begin{array}{c}\text { Emergencia } \\
(\%)\end{array}$ & $\begin{array}{c}\text { Plântulas com sintomas } \\
\text { da mancha reticulada(\%) }\end{array}$ \\
\hline Disenoconazole 25 & $96,5 \mathrm{~b}^{\star}$ & $1,75 \mathrm{~b}$ \\
Difenoconazole 30 & $97,6 \mathrm{a}$ & $4,75 \mathrm{~b}$ \\
Iprodione+Thiram 50+150 & $97,0 \mathrm{ab}$ & $1,25 \mathrm{~b}$ \\
Triadimenol 40 & $94,6 \mathrm{C}$ & $5,75 \mathrm{~b}$ \\
Tebuconazole 15 & $93,6 \mathrm{~d}$ & $5,00 \mathrm{~b}$ \\
Testemunha & $89,0 \mathrm{~d}$ & $30,00 \mathrm{a}$ \\
& & \\
\hline C.V. (\%) & 0,47 & 41,40 \\
Média geral & 94,7 & 8,08 \\
& & \\
\hline
\end{tabular}

* Médias seguidas da mesma letra não diferem pelo teste de Duncan ao nivel de $5 \%$. 
Tabela 3 - Efeito do tratamento de sementes sobre o comprimento de coleóptilo $(\mathrm{cm})$ e radícula $(\mathrm{cm})$. Santa Maria, 1993.

\begin{tabular}{lll}
\hline $\begin{array}{l}\text { Tratamentos } \\
\text { (g/100kg de sementes) }\end{array}$ & $\begin{array}{c}\text { Coleoptilo } \\
(\mathrm{cm})\end{array}$ & $\begin{array}{l}\text { Radicula } \\
(\mathrm{cm})\end{array}$ \\
\hline Difenoconazole 25 & $14,10 \mathrm{~b}$ & $16,66 \mathrm{bc}$ \\
Difenoconazole 30 & $14,24 \mathrm{~b}$ & $12,99 \mathrm{~d}$ \\
Iprodione + Thiram $50+150$ & $14,52 \mathrm{~b}$ & $14,52 \mathrm{C}$ \\
Triadimenol 40 & $11,24 \mathrm{C}$ & $17,40 \mathrm{~b}$ \\
Tebuconazole 15 & $13,45 \mathrm{~b}$ & $19,09 \mathrm{ab}$ \\
Testemunha & $15,91 \mathrm{a}$ & $21,39 \mathrm{a}$ \\
& & \\
\hline C.V. (\%) & 8,42 & 16,30 \\
Media Geral & 13,91 & 17,01 \\
\end{tabular}

* Médias seguidas da mesma letra não diferem pelo teste de Duncan ao nivel de $5 \%$.

Conforme os resultados obtidos recomendase o tratamento de sementes de cevada com fungicidas pois é uma prática capaz de atrasar os ciclos secundários da doença bem como auxiliar na otimizaçăo dos rendimentos, devendo-se considerar, também, o sugerido por REIS (1985) em que a redução nos níveis de infecçăo de $\boldsymbol{H}$. teres em sementes de cevada é o resultado da soma de várias práticas aplicadas, e năo somente através do tratamento de sementes.

Na Tabela 4, são apresentados os patógenos recuperados a partir de sementes tratadas com os fungicidas testados a campo, sendo observado que Iprodione + Thiram e Triadimenol apresentaram 0 maior efeito inibidor contra todos patógenos presentes nas sementes analizadas; Difenoconazole (25 e $30 \mathrm{~g}$ ) e Tebuconazole nåo foram eficientes contra Fusari um sp. Pelos dados obtidos atesta-se a seletividade dos produtos e a necessidade de utilizá-los em misturas para que tenham seu efeito fungicida maximizado.

\section{REFERÊNCIAS BIBLIOGRÁFICAS}

BALARDIN, R.S., LOCH, L.C. Efeito de thiram sobre a germinaçăo de sementes de centeio e aveia. Revista Brasileira de Sementes, Brasilla, v. 9, n. 1, p. 113-117, 1987.

BARNETT, H.L., HUNTER, B.B. Illustrated genera of imperfect fungi. 3. ed. Minneapolis: Burgess, 1972. 241 p.
Tabela 4 - Efeito do tratamento de sementes sobre os patogenos presentes na semente. Santa Maria, 1993.

\begin{tabular}{lcccccc}
\hline \multicolumn{1}{c}{ Tratamentos } & \multicolumn{5}{c}{ Patogenos $^{*}$} \\
(g/100kg de sementes) & 1 & 2 & 3 & 4 & 5 \\
& & & & & \\
\hline & 20 & 1 & 0 & 6 & 2 \\
Difenoconazole 25 & 12 & 3 & 4 & 1 & 0 \\
Difenoconazole 30 & 4 & 1 & 0 & 0 & 0 \\
Iprodione + Thiram 50+150 & 2 & 1 & 1 & 3 & 0 \\
Triadimenol 40 & 13 & 0 & 0 & 6 & 0 \\
Tebuconazole 15 & 20 & 7 & 1 & 14 & 8 \\
Testemunha & & & & & \\
\hline
\end{tabular}

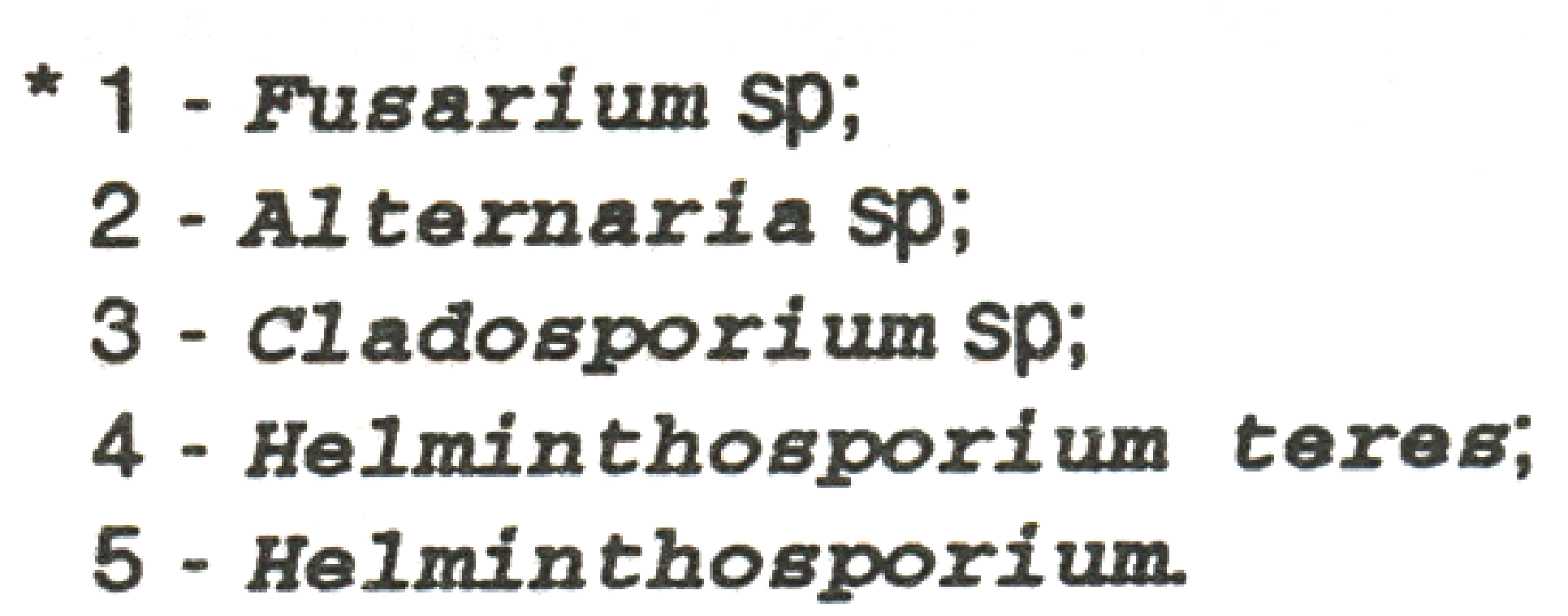

FORCELINI, C.A., REIS, E.M. Efeito do tratamento de sementes de cevada com fungicidas no controle e desenvolvimento da mancha reticulada na folha causada por Helminthosporium teres (Pyrenophora teres). Fitopatologia Brasileira, Brasilia, v. 12, n. 1 , p. $83-87,1987$.

HAVAGGE, C.A.C., SILVA, A.C. da. Efeito do tratamento da semente com fungicidas sobre a emergencia em campo e doenças foliares da cevada. Revista Brasileira de Sementes, Brasilia, v. 2, n. 1, p. 107-112, 1980.

LARGE, E.C. Growth stages in cereals, Illustration of the Feeks scale. Plant Patholov, Londres, v. 3, p. 128-129, 1956.

LUZ, W.C. da. Ocorrencia de Pyrenophora teres (Died.) Drech. em sementes de cevada Hordeun vulgare L.) no Brasil. Fitopatologia Brasileira, Brasilia, v. 5, n. 3, p. 273-276, 1980.

LUZ, W.C. da. Diagnose das doenças da cevada no Brasil. Passo Fundo: EMBRAPA-CNPT, 1982. 24 p. Circular Técnica, 2.

LUZ, W.C. da. Effects de fungicides systemiques utilises en traitement des semences sur la rayure reticulee de l'orge. Fitopatologia Brasileira, Brasília, v. 7, n. 2, p. 169-173, $1982 a$.

LUZ, W.C. da., MINELLA, E. Microorganismos das sementes de cevada em diferentes locais do Brasil. Fitopatologia Brasileira, v. 7, n. 3, p. 387-391, 1982.

NEERGAARD, P. Detection of seed-borne pathogens by culture tests. Seed Sci \& Technol, Copenhagen, v. 1, p. 217-254, 1973.

REIS, E.M. Podridấo de raizes seminais e lesões foliares do trigo (Triticum aestivum L.) associados a Helminthosporium sat i vum Pamm., King \& Bakke, transmitido pela semente. Summa Phytopathologica, Jaguariuna, v. 7, n. 3-4, p. 39-44, 1981.

REIS, E.M. Estratégia para a produçăo de sementes de cevada Ivres de Helminthosporium (Pyrenophora) teres. Boletim Informativo - APASSUL, Passo Fundo, v. 1, n. 7, p. 3, 1985. 